\title{
HIGH GRADIENT DIELECTRIC WAKEFIELD DEVICE MEASUREMENTS AT THE ARGONNE WAKEFIELD ACCELERATOR
}

\author{
P. Schoessow, M. Conde, W. Gai, R. Konecny, J. Power, and J. Simpson \\ Argonne National Laboratory, 9700 S. Cass Ave. Argonne IL 60439
}
The submitted manuseript has been authorec by a contractor of the U.S. Governmen under cantract No. W-31-109ENG-38
Accordingly, the U.S. Government retains : Accordingly, the U.S. Government retains ?
nonexclusive, rovalty-free license to publist or reproduce the published form of thi: contribution, or allow others to do so, fo U. S. Government purposes.

\section{Abstract}

The Argonne Wakefield Accelerator (AWA) is a facility designed to investigate high gradient wakefield acceleration techniques. Wakefields are excited using a drive beam produced by a $14 \mathrm{MeV}$ high current photoinjector-based linac. A second photocathode gun generates a $4 \mathrm{MeV}$ witness beam which is used as a probe of the wakefields in the device under test. The delay of the witness bunch with respect to the drive bunch can be continuously varied from $-100 \mathrm{ps}$ to $>1 \mathrm{~ns}$. The drive and witness bunches propagate along collinear or parallel trajectories through the test section. A dipole spectrometer is then used to measure the energy change of the witness beam. The complete wakefield measurement system has been commissioned and wakefield experiments using dielectric structures are underway. Initial experiments have focused on collinear wakefield device geometries where the drive and witness bunches traverse the same structure. For attaining very high gradients we will construct and study stepup transformer structures in which the if pulse generated by the drive beam is compressed transversely and longitudinally.

\section{INTRODUCTION}

Research on dielectric loaded structures as high energy wakefield accelerators has been proceeding for some time [1]. These devices possess some obvious advantages:

- Simplicity of fabrication.

- Parasitic wakë control and suppression. The $\mathrm{HEM}_{11}$ mode is in general lower in frequency than the $\mathrm{TM}_{01}$ accelerating mode [2], providing greater tolerance to the beam breakup instability than conventional structure based accelerators. Multibunch beam breakup effects can also be controlled with a simple mode suppression scheme [3].

- Adaptability to a two-beam (transformer) configuration [4]. In this technique the wake generated by multiple drive bunches in a low impedance dielectric structure is coupled into a high impedance structure. This provides a transformer ratio enhancement as well as simplifying the staging of the drive and witness beams.

There are also potential difficulties with dielectric devices:

- Breakdown limits at high fields.

- Charging from intercepted beam halo.

- Radiation damage effects on dielectric properties.

Initial experiments at AATF [5] concentrated on understanding the low-field regime. One of the primary goals of the AWA program is to study the physics of dielectric wakefield structures at high gradients with the emphasis on developing techniques useful for high energy accelerators. We report here the results of our initial experiments on collinear drive-witness beam geometry, and describe planned experiments with transformer structures.

\section{WAKEFIELD MEASUREMENT SYSTEM}

The AWA has been described in detail elsewhere $[6,7]$. In brief, the facility consists of a unique high current photoinjector and linac which generates the drive beam, a second high brightness photoinjector which produces the witness beam, beamlines to transport drive and witness beams through the wakefield device under test, and a magnetic spectrometer to measure the change in energy of the witness beam from the wakefield of the drive beam.

The drive beam intensity is monitored using an integrating current transformer immediately upstream of the test section. The length of the drive beam can be measured using an aerogel Cherenkov radiator which can be inserted into the beamline. Light produced in the radiator is then transported to a streak camera.

The drive and witness guns share a common laser system. A portion of the laser pulse is split off and directed through an optical trombone before being transported to the witness gun to adjust the delay between the two beams. At the same time the phase of the if driving the witness gun is varied to maintain a constant laser injection phase.

The witness beam is detected at the $60^{\circ}$ port of the spectrometer using a phosphor screen and intensified CCTV camera. The energy acceptance of the spectrometer is $\pm 165 \mathrm{keV}$; for all but the lowest gradient device measurements the spectrometer

Submitted to the proceedings of the 1997 Particle Accelerator Conference, Vancouver, BC, May 12-16, 1997. 


\section{DISCLAIMER}

This report was prepared as an account of work sponsored by an agency of the United States Government. Neither the United States Government nor any agency thereof, nor any of their employees, makes any wartanty, express or implied, or assumes any legal liability or responsibility for the accuracy, completeness, or usefulness of any information, apparatus, product, or process disclosed, or represents that its use would not infringe privately owned rights. Reference herein to any specific commercial product, process, or service by trade name, trademark, manufacturer, or otherwise does not necessarily constitute or imply its endorsement, recommendation, or favoring by the United States Government or any agency thereof. The views and opinions of authors expressed herein do not necessarily state or reflect those of the United States Government or any agency thereof. 


\section{DISCLAMTER}

Portions of this docoment may be illegible in electronic image prodnets. Images are produced from the best available original docoment 
current was adjusted to center the witness beam on the phosphor as the delay was varied. The spectrometer current was then recorded for each delay setting as a measure of the wake potential for that delay.

\section{DIELECTRIC DEVICE MEASUREMENTS}

Initial experiments were performed using simple collinear dielectric structures. These devices were fabricated from borosilicate glass which has a dielectric constant $\approx 4$ and is known from measurements at the AATF to be resistant to charging.

\section{$3.115 \mathrm{GHz}$ device delay scan}

The wake potential for a $15 \mathrm{GHz}$ structure (inner radius $a=5 \mathrm{~mm}$, outer radius $b=7.7 \mathrm{~mm}$, length $=11$ $\mathrm{cm}$ ) was mapped out in detail. For this measurement only a modest drive beam charge $(11 \mathrm{nC} /$ pulse $)$ was used. The bunch length was not measured but was estimated to be about $10 \mathrm{ps}$ rms. The witness gun delay was increased in 5 ps steps (later in the run changed to $10 \mathrm{ps}$ increments) from $0-400 \mathrm{ps}$. The image of the witness beam spot on the phosphor screen downstream of the spectrometer was digitized at each delay setting and saved to disk for offline analysis.

Figure 1 shows the accelerating gradient as measured from the energy change of the centroid of the witness beam as a function of the delay. The largest energy change corresponds to a gradient $\approx 2$ $\mathrm{MeV} / \mathrm{m}$

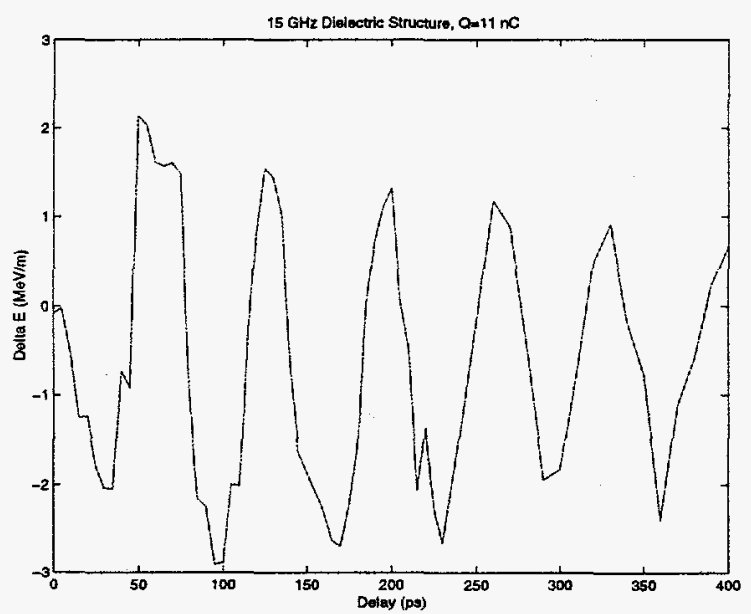

Figure 1. Longitudinal wakefield as measured from centroids of the witness beam energy distribution for $15 \mathrm{GHz}$ dielectric structure.

Additional optimization of the laser injection phase and beamline magnet settings resulted in a gradient of $7 \mathrm{MeV} / \mathrm{m}$ with $20 \mathrm{nC}$ drive beam intensity. This agrees well with calculations assuming $\sigma_{z}=2.5$ $\mathrm{mm}$ (8.3 ps).
$3.220 \mathrm{GHZ}$ device- gradient vs drive charge and bunch length

In order to increase transmission of the drive beam through smaller (higher impedance) wakefield devices, a quad triplet was located upstream of the wakefield device. The improved optics allowed up to $40 \mathrm{nC}$ drive charge/pulse to be transmitted through a 3 $\mathrm{mm}$ radius aperture $10 \mathrm{~cm}$ in length. At these intensities background from $\mathrm{X}$-rays and secondary electrons from drive beam scraping caused problems for witness beam detection. After careful radiation shielding and with improved beam monitoring the background became manageable.

A $20 \mathrm{GHz}$ device $(a=2.9 \mathrm{~mm}, b=5.0 \mathrm{~mm})$ was used to study wakefield effects as a function of drive beam intensity and length. The drive beam current was gradually increased by removing neutral density filters in the laser transport line for the drive gun. The beam transport lines were retuned to give maximum transmission for each drive beam intensity. At each point the gradient (maximum witness beam energy change) was measured, along with the drive bunch length.

Drive charges for this experiment were in the

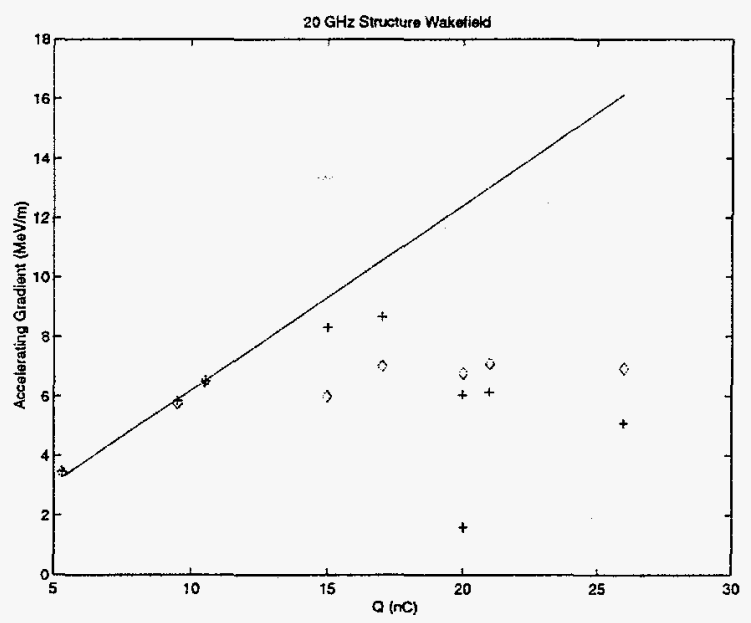

Figure 2. Wakefield gradient vs charge for $20 \mathrm{GHz}$ structure. Diamonds: AWA measurements. Straight line: predicted gradient based on $10.5 \mathrm{nC}$ measurement. Crosses: predicted gradient based on $10.5 \mathrm{nC}$ point and measured bunch length at each charge.

$5-25 \mathrm{nC}$ /pulse range. Rms drive bunch lengths were found to vary from $6 \mathrm{ps}$ at $5 \mathrm{nC}$ to $20 \mathrm{ps}$ at $25 \mathrm{nC}$. This increase in bunch length resulted in a rolloff in the observed wakefield gradient with drive charge as shown in Figure 2. The Figure also shows the predicted gradient if the length of the drive bunch had not increased with charge, and also the predicted gradient based on the expected $\exp \left(-k^{2} \sigma^{2} / 2\right)$ scaling with bunch length. The scaled gradient generally reproduces the trend of the data. 
According to the latest results from beam characterization/optimization experiments [7], where rms bunch lengths of $3 \mathrm{~mm}$ at $50 \mathrm{nC}$ have been attained, a gradient of $25 \mathrm{MeV} / \mathrm{m}$ should be possible. It is important to point out that at the present time the observed accelerating gradient is $>7 \mathrm{MeV} / \mathrm{m}$, i.e. larger by a factor of $>10$ than the maximum gradients obtained in the earlier AATF experiments [5].

\section{WAKEFIELD TRANSFORMER EXPERIMENTS}

The next wakefield experiments planned for the AWA include the demonstration of dielectric step-up transformers. A $15.6 \mathrm{GHz}$ device was chosen for the initial measurement because of its potential for producing high gradients while being well matched to the present performance of the AWA wakefield measurement system. Table I shows two possible configurations for a $15.6 \mathrm{GHz}$ transformer experiment. Transformer ratios of $4-5$ can be obtained. Techniques for efficient coupling of if into dielectric structures have been developed [9]; these results are directly relevant for the fabrication of transformer structures.

The AWA wakefield measurement system also possesses the capability of transporting the witness beam parallel but at a transverse offset with respect to the drive beam; in fact this mode of operation should greatly simplify data taking since the $4 \mathrm{MeV}$ witness and $14 \mathrm{MeV}$ drive beam no longer need to be transported through the same beam optics upstream of the test section. Thus direct measurements of the gradient and transformer ratio will be possible. The drive bunch parameters shown in Table 1 correspond to beams presently available at the AWA. Initial measurements will use a single drive bunch to verify rf coupling between structures and demonstrate a transformer ratio $>2$. A laser beam splitter system has been obtained for multiple drive bunch measurements.

\section{DISCUSSION}

Wakefield acceleration in dielectric structures has been studied at gradients significantly higher than demonstrated previously. At $7 \mathrm{MeV} / \mathrm{m}$ no sign of dielectric breakdown was observed. Despite a large intercepted beam from missteering during tuning and halo, charging of the borosilicate glass dielectric was not found to be a problem.

The AWA is well along in attaining its performance goals in terms of drive beam current transported through a wakefield device. The initial experiments demonstrate that the technology of dielectric wakefield structures is a very promising one for use in high energy accelerators.

\section{ACKNOWLEDGEMENT}

This work is supported by the Department of Energy, Division of High Energy Physics, under contract W-31-109-ENG-38.

\section{REFERENCES}

[1] R. Keinigs et al., Part. Accel. 24223 (1989)

[2] M. Rosing, W. Gai, Phys. Rev. D42 1829 (1990)

[3] E. Chojnacki et al., J. Appl. Phys. 696257 (1991)

[4] E. Chojnacki et al., Proc. 1991 Particle

Accelerator Conference, p. 2557-2559

[5] W. Gai et al., Phys. Rev. Lett. 61 (2756) 1988

[6] W. Gai et al., Advanced Accelerator Concepts, Lake Tahoe CA 1996, S. Chattopadhyay ed. (in press).

[7] M. Conde et al., these Proceedings

[8] W. Gai et al., these Proceedings

[9] W.Gai, R. Konecny, J. Simpson, these Proceedings

\begin{tabular}{|c|c|c|c|}
\hline & $\begin{array}{l}\text { Stage } \\
\text { I }\end{array}$ & $\begin{array}{l}\text { Stage II } \\
\text { (option 1) }\end{array}$ & $\begin{array}{l}\text { Stage II } \\
\text { (option 2) }\end{array}$ \\
\hline $\begin{array}{l}\text { Inner radius a } \\
\text { (mm) }\end{array}$ & 5 & 1.5 & 1.5 \\
\hline $\begin{array}{l}\text { Outer radius } \\
b(\mathrm{~mm})\end{array}$ & 8.1 & 2.38 & 2.7 \\
\hline $\begin{array}{l}\text { Dielectric } \\
\text { constant } \varepsilon\end{array}$ & 3.0 & 35 & 20 \\
\hline $\begin{array}{l}\text { Charge/ pulse } \\
\text { (nC) }\end{array}$ & 40 & & \\
\hline $\begin{array}{l}\text { rms bunch } \\
\text { length (mm) }\end{array}$ & 2.5 & & \\
\hline $\begin{array}{l}\text { Wake } \\
\text { amplitude/ } \\
\text { acceleration } \\
\text { gradient } \\
\text { (MV/m) }\end{array}$ & 16.2 & 79 & 65 \\
\hline $\begin{array}{l}\text { Number of } \\
\text { drive pulses }\end{array}$ & & 20 & 20 \\
\hline $\begin{array}{l}\text { Transformer } \\
\text { ratio }\end{array}$ & & 4.9 & 4 \\
\hline $\begin{array}{l}\text { Energy gain } \\
(\mathrm{MeV})\end{array}$ & & 79 & 108 \\
\hline
\end{tabular}

Table 1. Parameter sets for two possible $15.6 \mathrm{GHz}$ wakefield transformers. 